\title{
PENINGKATAN PRODUKSI RUMAH BATIK SITI KHADIJAH, KECAMATAN MEDAN TIMUR, PROVINSI SUMATERA UTARA
}

\author{
Harris P. Nasution' ${ }^{1}$, Djames ${ }^{2}$, Nursiah ${ }^{3}$ \\ 1,2,3Politeknik Negeri Medan, Kota Medan, Indonesia \\ email : harrisnasution@polmed.ac.id,djames@polmed.ac.id, nursiah@polmed.ac.id
}

\begin{abstract}
Abstrak: Berkembangnya batik Sumatera Utara menjadi suatu hal yang menarik untuk diperhatikan, karena industri ini sangat berpotensi dalam mengangkat budaya lokal dan menjadi alternatif pilihan di tengah-tengah tren batik yang kini sedang pesat dan maju bagi tren fashion. Rumah Batik Siti Khadijah di Jalan Gunung Mahameru Glugur Darat Medan, yang mengangkat batik dengan khazanah budaya lokal. Rumah Batik Siti Khadijah didirikan sekitar April 2018 dan produk yang dihasilkan berupa batik cap dan batik tulis dengan motif ornamen Sumatera Utara.

Proses produksi pembuatan batik khas Medan yang dilakukan dirumah produksinya, namun saat ini kesulitan saat produksi dalam melakukan desain motif cetak karena komputer dan printer hanya 1 unit yang juga digunakan untuk kegiatan administrasi/pembukuan. Faktor keterbatasan dana yang membuat rumah produksi masih menggunakan 1 unit komputer PC saja.

Kendala keterbatasan proses produksi terutama desain motif-motif dari Rumah Batik dapat diatasi dengan penerimaan alat produksi berupa Laptop yang diberikan Tim PKM. Selain itu melalui pemberian pelatihan pemasaran dengan mempergunakan media online dan offline dengan strategi yang tepat, akan membuat produk Rumah Batik ini lebih dikenal khalayak.
\end{abstract}

Kata kunci : Produksi, Batik khas, Rumah Batik Siti Khadijah

Abstract: The development of North Sumatran batik is an interesting thing to know, because this industry has the potential to raise of local culture and become an alternative choice in the midst of batik trends that are currently rapidly and advancing for fashion trends. Siti Khadijah Batik House on Jalan Gunung Mahameru, Glugur Darat Medan, which features batik with local cultural treasures. The Siti Khadijah Batik House was established around April 2018 and the products produced are stamped batik and written batik with North Sumatran ornamental motifs.

The production process for making batik from Medan is carried out at the production house, but currently it is difficult during production to design print motifs because only 1 pcs computer and printer are used for administrative/bookkeeping activities. The factor of limited funds that makes the production house still uses only 1 pCs PC computer.

The constraints of the limited production process, especially the design of the motifs from Rumah Batik, can be overcome by accepting the production equipment in the form of a laptop given by the PKM Team. In addition, through the provision of marketing training using online and offline media with the right strategy, this Batik house product will be better known to the public.

Keywords: Production, Typical Batik, Siti Khadijah's Batik House

\section{Pendahuluan}

Pada era modern sekarang ini batik bukanlah identic sebgai pakaian formal saja yang hanya dipakai untuk kegiatan pesta atau undangan tapi fungsinya sudah berkembang. Semenjak baju batik Indonesia telah ditetapkan oleh UNESCO sebagai salah satu warisan budaya, penggunaan batik telah berkembang pesat terutama di kota-kota besar di seluruh Indonesia. Batik berkembang di seluruh penjuru Indonesia, termasuk Sumatera Utara. Batik Sumatera Utara muncul dengan ornamen-ornamen khas daerah yang ada di Sumatera Utara, seperti Batak Toba, Mandailing, Tapanuli Tengah, Simalungun, Pakpak, Dairi, Karo, 
Melayu Deli dan Nias. Batik adalah seni gambar di atas kain untuk pakaian. Seni gambar ini tidaklah asal menggambar saja akan tetapi motif apa yang digambar juga memiliki makna filosofis.( Iskandar dan Kustiyah. 2017, Jurnal Gema)

Batik Sumatera Utara sendiri memiliki ciri khas dan hadir dengan beragam motif etnik khas Sumatera Utara yang tampil atraktif dengan motif ornamen dari berbagai macam suku yang ada di wilayah Sumatera Utara, seperti ornamen Batak Toba, Mandailing, Tapanuli Tengah, Simalungun, Pakpak, Dairi, Karo, Melayu Deli dan Nias. Berkembangnya batik Sumatera Utara menjadi suatu hal yang menarik untuk diperhatikan, karena industri ini sangat berpotensi dalam mengangkat budaya lokal dan menjadi alternatif pilihan di tengah-tengah tren batik yang kini sedang pesat dan maju bagi tren fashion. (Ramadini dan Nasution, 2016)

Bahwa pengembangan ekonomi daerah yang bertujuan meningkatkan kesejahteraan masyarakat, maka pengembangan ekonomi lokal sesuai potensinya menjadi sangat penting. Dengan keunggulan yang dimiliki, usaha kecil dan menengah (UKM) menjadi sangat penting untuk mewujudkan pengembangan perekonomian daerah dan pemberdayaan masyarakat (Sulistyastuti 2004, Jurnal Ekonomi Pembangunan). Hal ini untuk dapat lebih meningkatkan bagi keunggulan dan perkembangan UKM tersebut kedepannya.

Jumlah Perajin yang melirik peluang usaha dari bisnis dari batik terus bertumbuh. Salah satunya, Rumah Batik Siti Khadijah yang mengangkat batik dengan khazanah budaya lokal. Rumah Batik ini adalah salah satu rumah produksi batik Sumatera Utara yang terletak di Jl. Gunung Mahameru No. 2 Medan dan didirikan sekitar April 2018. Usaha ini dikelola oleh Ibu Beby Indah yang sebelumnya pernah mengikuti pelatihan membatik di Yogyakarta dan Pekalongan. Modal awal usaha ini sebesar Rp. 50.000.000,- (lima puluh juta) dengan produk batik yang dihasilkan yaitu batik cap dan batik tulis dengan motif ornamen Sumatera Utara.

Teknologi produksi yang digunakan masih tradisional dengan alat-alat khas membatik. Para pekerja pada UKM ini berjumlah 8 orang yang melibatkan penduduk yang tinggal di sekitar Rumah Batik Siti Khadijah. Status kepemilikan tanah tempat usaha ini adalah sertifikat hak milik dan investor usaha yang dikelola adalah anggota keluarga pemilik dan sanak saudara. (Siregar, 2021)

Pengelola usaha Rumah Batik Siti Khadijah, baru-baru ini menyebutkan, prospek batik masih cukup cerah. Hal ini yang memotivasinya bersama keluarga besar mencoba merintis usaha batik sekaligus rumah produksinya. Selain membuat dan menjual batik, pihaknya juga menerima pesanan sesuai motif yang diinginkan. Rumah Batik Siti Khadijah ini juga sekaligus tempat workshop bagi para pelajar dan siapa saja yang suka dengan batik. (sumber : https://www.ukmkotamedan.com)

Dalam mengembangkan usaha, masalah utama yang dihadapi adalah modal, bahan baku, sumber daya manusia yang terampil dan masih banyak yang belum tahu tentang keberadaan batik khas Medan ini. Khusus yang utama bahan baku yang dibutuhkan saat ini diperoleh dari Pekalongan dan Solo sehingga membutuhkan waktu yang lama dalam produksi karena peroses pengiriman butuh waktu. Tetapi perkembangan batik sebagai ekonomi kreatif yang semakin luas pemakaiannya dan coraknya semakin beragam ini tidak diimbangi dengan regenerasi para pembatik, terutama batik tulis. (Rosyada dan Tamamudin, 2020) 
Kemudian pemilik Rumah Batik menceritakan proses produksi pembuatan batik khas Medan yang dilakukan dirumah produksinya, " Dalam proses pembuatan ada langkah yang harus dikerjakan yaitu pertama, prosesnya dimulai dari membuat desain motif khas Medan atau sesuai dengan selera dari konsumen dan biasanya kita menampilkan berbagai motif dari komputer yang sudah kita simpan dalam file motif ". Namun saat ini kesulitan saat produksi dalam memilih motif ini karena komputer dan printer hanya 1 unit yang juga digunakan untuk kegiatan administrasi/pembukuan. Faktor keterbatasan dana saat ini rumah produksi masih menggunakan 1 unit komputer PC saja. Kemudian setelah memilih motif dilakukan print dan dicetak menggunakan lilin, dicolet (diwarnai bagian-bagian motif), Jos (menghilangkan bekas-bekas cetakan lilin yang tidak bagus), kunci (mempermanenkan warna motif), proses pencucian, Nembok (menutup warna motif yang ada dengan bioglass), warna (membuat warna untuk dasar kain) pada akhirnya dilakukan Lorot (proses akhir sebelum kain siap dijual). (Indah. 2021)

Pemilik usaha pembuatan batik masih mengandalkan bahan baku yang didatangkan dari Pekalongan, sehingga harga batik tidak mungkin lebih murah lagi, sebab mutu atau kualitas juga harus diutamakan. "Intinya, usaha ini juga untuk membuka lapangan kerja serta sarana belajar keterampilan bagi para pelajar untuk membatik". (sumber: https://www.ukmkotamedan.com)

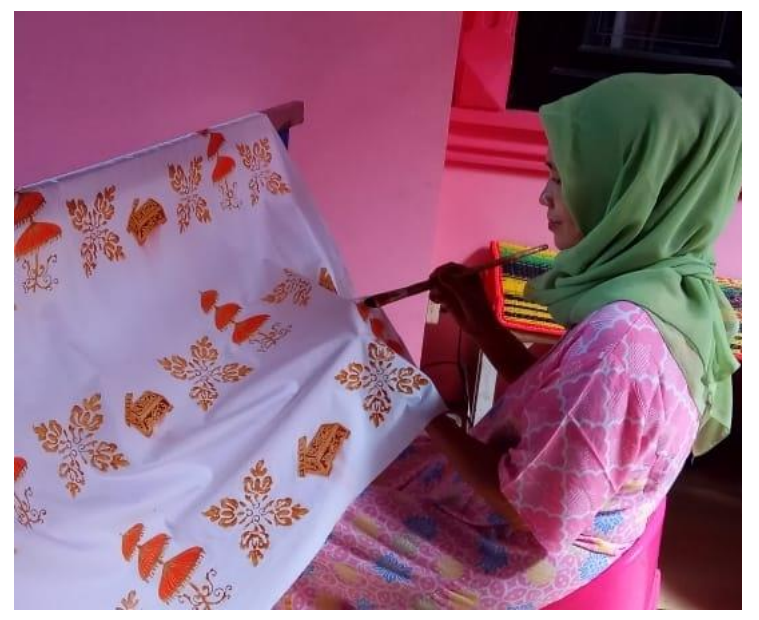

Gambar 1. Pekerja batik sedang melukis di kain

Dalam pendistribusian produk, pelaku UKM menggunakan distribusi langsung kepada konsumen dengan membuka toko penjualan di sebelah rumah produksi dan juga menerima orderan dari pelanggan. Selain itu dalam promosi juga memanfaatkan media social yang digunakan untuk mempromosikan produk usaha batik namun masih terbatas. Harga jual batik pada UKM ini berkisar antara Rp. 140.000,- untuk kain katun (tergantung motif dan warna) dan Rp. 160.000,- untuk kain dobi (tergantung motif dan warna). Selain membuat dan menjual batik, pihaknya juga menerima pesanan sesuai motif yang diinginkan. Rumah Batik Siti Khadijah ini juga sekaligus tempat workshop bagi para pelajar dan siapa saja yang suka dengan batik.

Pengelola usaha Rumah Batik Siti Khadijah, mengatakan bahwa prospek batik masih cukup cerah. Hal ini yang memotivasinya bersama keluarga besar mencoba merintis usaha batik sekaligus rumah produksinya. Keinginan kedepan nantinya usaha Rumah Batik ini ingin membuat banyak motif berdasarkan keragaman suku yang ada di Medan dan membeli peralatan yang lebih canggih seperti mesin cetak batik. 


\section{Metode}

Metode pelaksanaan kegiatan PKM meliputi:

1. Tahap Persiapan

Tahap persiapan meliputi:

a. Pada tahap persiapan hal yang pertama dilakukan dengan analisis kebutuhan terhadap permasalahan yang dihadapi mitra Rumah Batik. Pada proses ini juga berbagai kemungkinan program dibicarakan dengan pihak-pihak yang akan terlibat dengan kegiatan ini, seperti diskusi langsung dengan pengelola Ibu Beby Indah yang menjadi target audience. Kegiatan ini telah dilakukan pada hari Jum'at, 5 Maret 2021 dengan melakukan kunjungan langsung dan melihat tempat produksi.

b. Pada tahap persiapan kedua ini dilakukan persiapan mencari informasi terhadap kebutuhan Laptop yang dibutuhkan bagi mitra yang cocok untuk proses produksi awal dengan membuat desain dan mencetak motif batik. Selanjutnya menyiapkan bahan pelatihan untuk pembuatan blog dan menampilkan informasi-informasi yang penting di blog tersebut sebagai media promosi dan pemasaran.

c. Pada tahap persiapan ketiga dilakukan penentuan waktu pelatihan yang tepat bagi mitra dan tim pengabdian.

2. Tahapan Pelaksanaan. Pada tahapan ini akan dilaksanakan penyerahan/hibah berupa 1 unit Laptop serta dilakukan pelatihan pemasaran yang dapat dilakukan dengan 2 cara yaitu online dan offline. Secara online dengan memanfaatkan internet untuk pembuatan blog Rumah Batik Siti Khadijah serta juga memanfaatkan media sosial lainnya seperti : Facebook, instagram, twitter, dll. yang akan menampilkan produk-produk juga sekaligus menginformasikan dapat digunakan sebagai tempat workshop bagi para pelajar dan masyarakat yang ingin mencoba produksi batik secara hand made dari bahan batik lokal. Secara offline dengan menyarankan agar mengikuti pameran/event UKM yang ada di kota Medan.

Pelatihan ini dilaksanakan dengan jadwal satu kali pertemuan kepada pengelola UKM Rumah Batik Siti Khadijah berserta para pekerja yang berjumlah 8 orang.

Adapun rincian kegiatan yang direncanakan untuk program ini yaitu :

a. Pertemuan dengan pengelola UKM Rumah Batik Siti Khadijah di tempat usaha yang berada di Jl. Gunung Singgahmata (dekat Kampus UMSU) Kel.Glugur Darat I, Kec.Medan Timur, kota Medan. Tempat usaha ini juga merupakan tempat produksi batik ini dilakukan.

b. Memberikan bantuan 1 unit Laptop yang nanti akan digunakan hanya untuk kegiatan produksi saja sehingga pengerjaan mendesain dan mencetak motif menjadi lebih fokus dan cepat.

c. Kemudian lanjut memberikan pelatihan pemasaran kepada mitra UKM agar masyarakat dapat mengenal secara luas dengan melalui berbagai media online dan offline promosi UKM Rumah Batik Siti Khadijah.

d. Mempraktekkan dalam melakukan perawatan untuk bantuan produksi 1 unit Laptop bagi mitra sehingga daya tahan alat tetap dapat terjaga dan lebih awet. 


\section{Hasil dan Pembahasan}

\section{Persiapan}

Pada tahap persiapan Tim PKM Politeknik Negeri Medan Jurusan Administrasi Niaga mengunjungi mitra pada tanggal 28 November 2021 untuk melakukan diskusi dan rencana pelaksanaan serta tentang kesiapan mitra dalam menerima kunjungan tim. Selain itu juga tim PKM dan mitra menentukan waktu bagi pelaksanaan kegiatan dan telah disepakati Bersama untuk pelaksanaan kegiatan pada tanggal 4 Desember 2021.

\section{Pelaksanaan}

a. Tempat pelaksanaan. Kegiatan pengabdian dilaksanakan di Jl. Gunung Singgahmata (dekat Kampus UMSU) Kel.Glugur Darat I, Kec.Medan Timur, kota Medan dan berjarak sekitar $9 \mathrm{~km}$ dari kota Medan.

b. Kegiatan diawali dengan tim pengabdian menyerahkan bantuan alat produksi berupa 1 unit Laptop sebagai sarana penunjang utama bagi mitra dalam proses membuat batik cetak yang dimulai dengan melakukan pencarian motif dari sumber diinternet kemudian membentuk cetakan dari karton yang nanti akan dicetak pada kain polos sehingga terbentuk motif-motif batik. Pemberian alat produksi ini langsung diterima oleh manajer Bapak Rizal Siregar yang sangat berterima kasih karena sangat membantu bagi mitra yang membutuhkan alat produksi ini. Penyerahan bantuan 1 unit laptop oleh tim turut disaksikan oleh pekerja rumah batik dan mahasiswa pendamping pengabdian dari POLMED.

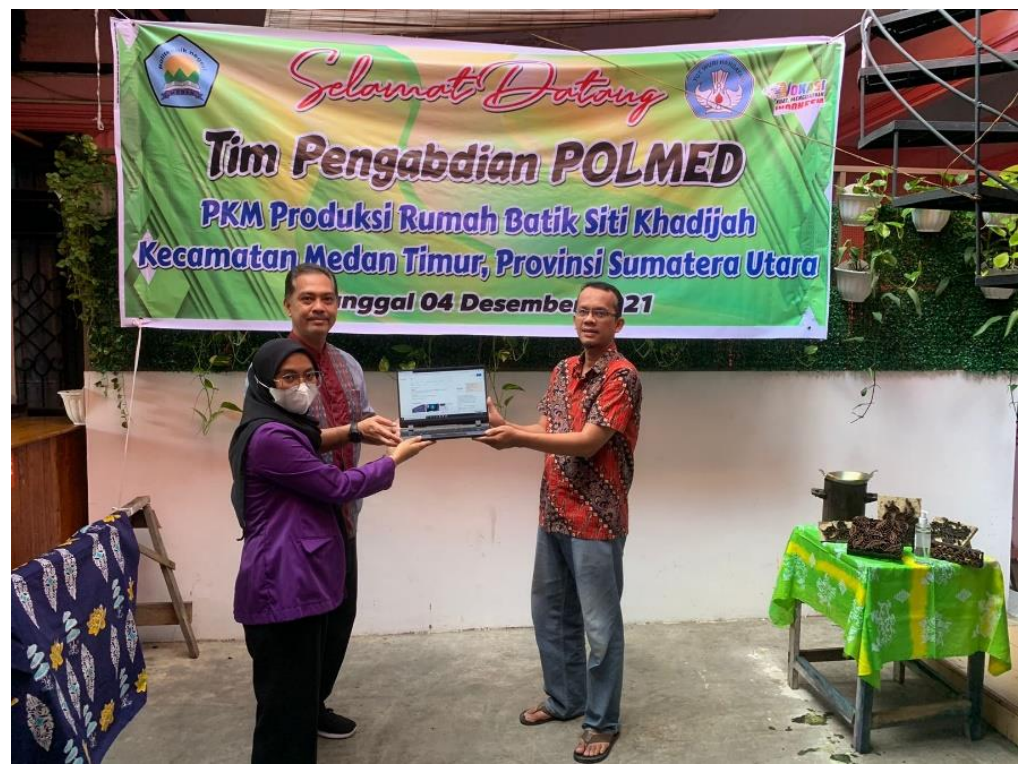

Gambar 2. Penyerahan alat produksi ke mitra Rumah Batik Siti Khadijah

Sosialisasi berupa pemberian pelatihan dari tim pengabdian kepada manajer Rumah Batik tentang strategi pemasaran telah membuka wawasan dalam memasarkan produk Batik kedepannya khusus dengan online atau digital. Seiring dengan kemajuan teknologi, tren di dunia bisnis juga semakin bervariasi. Salah satunya adalah tren digital marketing. (sumber: https://www. www.jurnal.id)

c. Saat ini pemasaran online yang dilakukan melalui FB, Instagram dan pemebritaan online namun untuk website belum ada. Pentingnya website sebagai media pemasaran adalah untuk memberikan informasi detail tentang produk yang anda tawarkan. Dengan memiliki website, nantinya calon pelanggan akan mengakses situs sebelum 
menghubungi perusahaan anda agar bisa mengenal lebih jauh tentang usaha rumah batik dan produk-produknya. Akan tetapi, suatu produk dengan penampilan terbaik atau bahkan dengan tampilan lebih baik bukanlah merupakan produk dengan kualitas tertinggi jika tampilannya bukanlah yang dibutuhkan dan diinginkan oleh pasar.(Anang Firmansyah. 2019)

\section{Evaluasi}

Pada tahap ini, dapat terlihat perbedaan inventaris milik mitra yang sebelumnya untuk proses mendesain motif masih menggunakan PC yang digunakan juga untuk kegiatan administrasi setelah dilakukan PKM ini mitra sudah dapat fokus dalam melakukan pencarian motif cetak dengan bantuan 1 unit Laptop untuk khusus proses produksi. Laptop ini juga nantinya dapat dipergunakan untuk kegiatan pemasaran online bagi mitra. Semua skala bisnis bisa memanfaatkan online marketing karena alat-alat yang diperlukan untuk digital marketing mudah diperoleh siapa saja. Cukup berbekal laptop dan koneksi internet, kita bisa menerapkan online marketing untuk bisnis kita jalankan. (sumber: https://www.niagahoster.co.id/)

\section{Kesimpulan}

1. Kendala keterbatasan proses produksi terutama desain motif-motif dari Rumah Batik dapat diatasi dengan penerimaan alat produksi berupa 1 unit Laptop yang diberikan Tim PKM.

2. Melalui pemberian pelatihan pemasaran dengan mempergunakan media online dan offline dengan strategi yang tepat, akan membuat produk Rumah Batik ini dikenal khalayak. Pengelola mulai memahami pentingnya sekarang ini pemasaran online karena pemesan sudah mulai tersebar diluar Sumatera, walaupun begitu tim masih memberikan pendampingan sampai dengan mendisain promo melalui internet.

\section{Ucapan Terima Kasih}

Program pengabdian kepada masyarakat ini merupakan salah satu wujud aplikasi Tridharma Perguruan Tinggi yang dilakukan sebagai dosen di Politeknik Negeri Medan yang harus senantiasa melakukan pengaplikasian ilmu melalui kegiatan pengabdian pada masyarakat. Pengabdian pada masyarakat ini dapat terlaksana dengan bantuan berbagai pihak. Untuk itu, pada kesempatan ini diucapkan terima kasih yang sebesar-besarnya kepada Politeknik Negeri Medan dan Pemilik Rumah Batik Siti Khadijah medan

\section{Daftar Pustaka}

Anang Firmansyah. M. "Pemasaran Produk Dan Merek (Planning \& Strategy)," CV. Penerbit Qiara Media. Cetakan pertama, 2019

D. Ratih Sulistyastuti. "Dinamika Usaha Kecil Dan Menengah (UKM) Analisis Konsentrasi Regional UKM di Indonesia 1999-2001", Jurnal Ekonomi Pembangunan Vol. 9 No. 2, Desember 2004, Hal: $143-164$

F. Ramadini dan I. Sari Nasution. "Strategi Pengembangan UKM Batik di Kota Medan", National Conference of Applied Sciences, Engineering, Business and Information Technology. Politeknik Negeri Padang, 15 - 16 Oktober 2016, ISSN:2541-111x Indah, Beby. (12 Juni 2021). Wawancara pribadi Pemilik Rumah Batik Siti Khadijah. 
Iskandar dan Kustiyah, Eny. "BATIK SEBAGAI IDENTITAS KULTURAL BANGSA INDONESIA DI ERA GLOBALISASI", Jurnal Gema, GEMA,THN XXX/52/Agustus 2016 - Januari 2017, Hal : $2456-2472$

Rosyada, Muhammad dan Tamamudin. "Pengembangan Ekonomi Kreatif Batik Tulis Kota Pekalongan Sebagai Upaya Pelestarian Budaya dan Peningkatan Pendapatan Masyarakat", Jurnal Darmabakti 01-02 (2020) 041050

Siregar, Reza Ansari. (12 Juni 2021). Wawancara pribadi pengelola Rumah Batik Siti Khadijah.

https://www.ukmkotamedan.com/angkat-budaya-lokal-rumah-batik-siti-khadijah-

tangkap-peluang-dari-batik? $v=1$ di akses tanggal 1 Maret 2021

https://www.jurnal.id/id/blog/mengenal-digital-marketing-konsep-dan-penerapannya/di

akses 14 Desember 2021

https://www.niagahoster.co.id/blog/online-marketing/ di akses 14 Desember 2021 